\title{
Comparative effectiveness of angiotensin-receptor blockers for preventing macrovascular disease in patients with diabetes: a population-based cohort study
}

\author{
Tony Antoniou PhD, Ximena Camacho MMath, Zhan Yao MSc, Tara Gomes MHSc, David N. Juurlink MD PhD, \\ Muhammad M. Mamdani MPH PharmD
}

See related commentary by Cooper on page 1023 and at www.cmaj.ca/lookup/doi/10.1503/cmaj.130507

\begin{abstract}
Background: Telmisartan, unlike other angiotensin-receptor blockers, is a partial agonist of peroxisome proliferator-activated receptor- $\gamma$, a property that has been associated with improvements in surrogate markers of cardiovascular health in small trials involving patients with diabetes. However, whether this property translates into a reduced risk of cardiovascular events and death in these patients is unknown. We sought to explore the risk of myocardial infarction, stroke and heart failure in patients with diabetes who were taking telmisartan relative to the risk of these events occurring in patients taking other angiotensinreceptor blockers.
\end{abstract}

Methods: We conducted a populationbased, retrospective cohort study of Ontario residents with diabetes aged 66 years and older who started treatment with candesartan, irbesartan, losartan, telmisartan or valsartan between Apr. 1, 2001, and Mar. 31, 2011. Our primary outcome was a composite of admission to hospital for acute myocardial infarction, stroke or heart failure. We examined each outcome individually in secondary analyses, in addition to all-cause mortality.
Results: We identified 54186 patients with diabetes who started taking an angiotensinreceptor blocker during the study period. After multivariable adjustment, patients who took either telmisartan (adjusted hazard ratio [HR] $0.85,95 \%$ confidence interval $[\mathrm{Cl}] 0.74-0.97$ ) or valsartan (adjusted HR 0.86, 95\% Cl 0.77-0.95) had a lower risk of the composite outcome compared with patients who took irbesartan. In contrast, no significant difference in risk was seen between other angiotensin-receptor blockers and irbesartan. In secondary analyses, we found a reduced risk of admission to hospital for heart failure with telmisartan compared with irbesartan (adjusted HR 0.79, 95\% Cl 0.66$0.96)$, but no significant differences in risk were seen between angiotensin-receptor blockers in our other secondary analyses.

Interpretation: Compared with other angiotensin-receptor blockers, telmisartan and valsartan were both associated with a lower risk of admission to hospital for acute myocardial infarction, stroke or heart failure among older adults with diabetes and hypertension. Telmisartan and valsartan may therefore be the preferred angiotensin-receptor blockers for use in these patients.
$\mathrm{A}$ bout 366 million people worldwide live with diabetes, a number that is projected to increase to 552 million by $2030 .{ }^{1} \mathrm{Be}$ cause disease-attributable macrovascular complications are the principal causes of death for people with type 2 diabetes, many therapies have the goal of reducing vascular events among these patients. ${ }^{2,3}$ Blockade of the renin-angiotensinaldosterone system with angiotensin-receptor blockers is a commonly used and particularly appealing strategy in this regard, given the multiple mechanisms through which angiotensin II contributes to a heightened risk of diabetes-related macrovascular disease and the superior tolerabil- ity profile of these drugs relative to angiotensinconverting enzyme (ACE) inhibitors. ${ }^{46}$

Although angiotensin-receptor blockers are considered largely interchangeable in clinical practice, evidence from experimental studies and small comparative trials suggest that telmisartan exhibits several pleoiotropic properties that distinguish it from other members of this drug class. ${ }^{7}$ Most notably, telmisartan is a partial agonist of peroxisome proliferator-activated receptor- $\gamma$ (PPAR $\gamma)$, a property associated with improvements in surrogate markers of cardiovascular health in small trials involving patients with type 2 diabetes. ${ }^{8-13}$ However, whether
Competing interests: Tony Antoniou has received unrestricted research grants from Merck and Pfizer. Tara Gomes has received grant funding for the Ontario Drug Policy Research Network from the Ontario Ministry of Health and Long-Term Care. Muhammad Mamdani serves on CMAJ's Editorial Advisory Board (but had no role in the decision to publish this paper), has been on other advisory boards and has received honoraria from AstraZeneca, Bristol-Myers Squibb, Eli Lilly and Company,

GlaxoSmithKline,

Hoffman-La Roche,

Novartis, Novo Nordisk,

Merck, Sanofi-Aventis and Pfizer. No other competing interests were declared.

This article has been peer reviewed.

Correspondence to: Tony Antoniou, tantoniou@smh.toronto.on.ca

CMAJ 2013. DOI:10.1503 /cmaj.121771 
telmisartan-mediated activation of PPAR $\gamma$ is associated with a reduced risk of macrovascular events in patients with diabetes relative to angiotensin-receptor blockers that do not share this property is unknown.

We sought to compare the risk of acute myocardial infarction, heart failure and stroke in older patients whose diabetes was also managed with either telmisartan or any of candesartan, irbesartan, losartan and valsartan. We speculated that, owing to its pleiotropic effects, telmisartan would be associated with a lower risk of macrovascular events in these patients relative to other angiotensin-receptor blockers.

\section{Methods}

\section{Study design}

We conducted a population-based retrospective cohort study involving Ontario residents with

Table 1 (part 1 of 2): Baseline characteristics of patients

\begin{tabular}{|c|c|c|c|c|c|}
\hline \multirow[b]{2}{*}{ Characteristic } & \multicolumn{5}{|c|}{ Angiotensin-receptor blocker, no. (\%)* } \\
\hline & $\begin{array}{l}\text { Telmisartan } \\
(n=8182)\end{array}$ & $\begin{array}{l}\text { Candesartan } \\
(n=10940)\end{array}$ & $\begin{array}{l}\text { Irbesartan } \\
(n=12691)\end{array}$ & $\begin{array}{l}\text { Losartan } \\
(n=8411)\end{array}$ & $\begin{array}{c}\text { Valsartan } \\
(n=13962)\end{array}$ \\
\hline Age, yr, median (IQR) & $73(69-78)$ & $73(69-79)$ & $73(69-78)$ & $73(69-79)$ & $73(69-78)$ \\
\hline \multicolumn{6}{|l|}{ Age group, yr } \\
\hline $66-74$ & $4929(60.2)$ & $6426(58.7)$ & $7603(59.9)$ & $4909(58.4)$ & $8197(58.7)$ \\
\hline $75-84$ & $2778(34.0)$ & 3778 (34.5) & $4342(34.2)$ & $2946(35.0)$ & $4863(34.8)$ \\
\hline$\geq 85$ & $475 \quad(5.8)$ & $736 \quad(6.7)$ & $746 \quad(5.9)$ & $556 \quad(6.6)$ & $902 \quad(6.5)$ \\
\hline Female sex & $4782(58.4)$ & $6579(60.1)$ & $7326(57.7)$ & $5238(62.3)$ & $8466(60.6)$ \\
\hline Duration of diabetes, yr, median (IQR) & $6.0(2.3-10.8)$ & $6.3(2.4-11)$ & $6.5(2.4-11.1)$ & $6.2(2.3-10.5)$ & $6.1(2.3-10.5)$ \\
\hline No admission to hospital & $6272(76.7)$ & $8177(74.7)$ & $9541(75.2)$ & $6351(75.5)$ & $10725(76.8)$ \\
\hline \multicolumn{6}{|l|}{ Charlson comorbidity index } \\
\hline 0 & $567 \quad(6.9)$ & $801 \quad(7.3)$ & $860 \quad(6.8)$ & $511 \quad(6.1)$ & $978 \quad(7.0)$ \\
\hline 1 & $595 \quad(7.3)$ & $801 \quad(7.3)$ & $940 \quad(7.4)$ & 661 (7.9) & 1000 \\
\hline$\geq 2$ & $748 \quad(9.1)$ & $1161(10.6)$ & $1350(10.6)$ & $888(10.6)$ & $1259 \quad(9.0)$ \\
\hline \multicolumn{6}{|l|}{ Reason for admission to hospital in previous $5 \mathrm{yr}$} \\
\hline Congestive heart failure & $519 \quad(6.3)$ & $989 \quad(9.0)$ & $957 \quad(7.5)$ & $755 \quad(9.0)$ & $(7.1)$ \\
\hline Angina & $163(2.0)$ & $(2.1)$ & $251 \quad(2.0)$ & $209 \quad(2.5)$ & (1.9) \\
\hline Diabetes & $347 \quad(4.2)$ & $(5.1)$ & $686 \quad(5.4)$ & $432(5.1)$ & $553 \quad(4.0)$ \\
\hline Hypertension & $2867(35.0)$ & $4234(38.7)$ & $4537(35.8)$ & $3252(38.7)$ & $5167(37.0)$ \\
\hline Stroke or transient ischemic attack & $261 \quad(3.2)$ & $417 \quad(3.8)$ & $443 \quad(3.5)$ & $312(3.7)$ & $431 \quad(3.1)$ \\
\hline Hypertrophic cardiomyopathy & $11 \quad(0.1)$ & $15 \quad(0.1)$ & $9 \quad(0.1)$ & $9 \quad(0.1)$ & $(0.1)$ \\
\hline Atrial fibrillation & $186 \quad(2.3)$ & $308 \quad(2.8)$ & $303 \quad(2.4)$ & $247 \quad(2.9)$ & $336 \quad(2.4)$ \\
\hline Ventricular dysrhythmia & $194 \quad(2.4)$ & $332 \quad(3.0)$ & $313 \quad(2.5)$ & $273 \quad(3.3)$ & (2.5) \\
\hline Peripheral vascular disease & $58 \quad(0.7)$ & $100 \quad(0.9)$ & $107 \quad(0.8)$ & $(0.9)$ & $(0.7)$ \\
\hline Percutaneous coronary intervention & $907(11.1)$ & $1402(12.8)$ & $1591(12.5)$ & $1091(13.0)$ & $1645(11.8)$ \\
\hline Coronary artery bypass grafting & $10 \quad(0.1)$ & $6 \quad(0.1)$ & $\leq 5 \quad(0.0)$ & $8 \quad(0.1)$ & $\begin{array}{ll}6 & (0.0)\end{array}$ \\
\hline History of chronic liver disease in $1 \mathrm{yr}$ & $92 \quad(1.1)$ & $153 \quad(1.4)$ & $180 \quad(1.4)$ & $122(1.5)$ & (1.5) \\
\hline History of chronic kidney disease in $1 \mathrm{yr}$ & $713 \quad(8.7)$ & $1262(11.5)$ & $1430(11.3)$ & $872(10.4)$ & 1148 \\
\hline Residence in a long-term care facility & 148 (1.8) & $206 \quad(1.9)$ & $243 \quad(1.9)$ & $146 \quad(1.7)$ & (1.6) \\
\hline No. of prescription drugs in previous $1 \mathrm{yr}$, median (IQR) & $8(5-12)$ & $9(6-12)$ & $8(6-12)$ & $8(5-12)$ & $8(5-12)$ \\
\hline \multicolumn{6}{|l|}{ Medications used in previous $1 \mathrm{yr}$} \\
\hline Angiotensin-converting enzyme inhibitors & $4740(57.9)$ & $6562(60.0)$ & $7833(61.7)$ & $4969(59.1)$ & $8372(60.0)$ \\
\hline Acetylsalicylic acid & $868(10.6)$ & $1296(11.9)$ & $1436(11.3)$ & $1091(13.0)$ & $1677(12.0)$ \\
\hline Other antiplatelet drugs & $209(2.6)$ & $326 \quad(3.0)$ & $363 \quad(2.9)$ & $204(2.4)$ & $332(2.4)$ \\
\hline$\beta$-adrenergic receptor antagonists & $1953(23.9)$ & $2734(25.0)$ & 3116 (24.6) & $1996(23.7)$ & $3372(24.2)$ \\
\hline Calcium-channel blockers & 2740 (33.5) & 3896 (35.6) & $4649(36.6)$ & $2805(33.4)$ & $4823(34.5)$ \\
\hline
\end{tabular}


diabetes aged 66 years and older who started treatment with either candesartan, irbesartan, telmisartan, losartan or valsartan between Apr. 1, 2001, and Mar. 31, 2010.

\section{Data sources}

We determined medication exposure using data from the Ontario Drug Benefit database, which contains comprehensive records of prescription drugs dispensed to Ontario residents aged
65 years and older. We excluded the first year of eligibility for prescription drug coverage (age $65 \mathrm{yr})$ to avoid having incomplete medication records. We obtained data on hospital admissions from the Canadian Institute for Health Information's Discharge Abstract Database, which contains detailed clinical information regarding all hospital admissions in Ontario. The abstraction of patient charts is undertaken by trained health information professionals using standard diagno-

Table 1 (part 2 of 2): Baseline characteristics of patients

\begin{tabular}{|c|c|c|c|c|c|}
\hline \multirow[b]{2}{*}{ Characteristic } & \multicolumn{5}{|c|}{ Angiotensin-receptor blocker, no. (\%)* } \\
\hline & $\begin{array}{l}\text { Telmisartan } \\
(n=8182)\end{array}$ & $\begin{array}{l}\text { Candesartan } \\
(n=10940)\end{array}$ & $\begin{array}{l}\text { Irbesartan } \\
(n=12691)\end{array}$ & $\begin{array}{l}\text { Losartan } \\
(n=8411)\end{array}$ & $\begin{array}{c}\text { Valsartan } \\
(n=13962)\end{array}$ \\
\hline \multicolumn{6}{|l|}{ Medications used in previous $1 \mathrm{yr}$} \\
\hline Thiazide diuretics & $1842(22.5)$ & $2338(21.4)$ & $2846(22.4)$ & $1810(21.5)$ & $2960(21.2)$ \\
\hline Aldosterone antagonists & $162(2.0)$ & $281 \quad(2.6)$ & $277 \quad(2.2)$ & $177(2.1)$ & $313(2.2)$ \\
\hline Other diuretic agents & $1533(18.7)$ & $2256(20.6)$ & $2654(20.9)$ & $1655(19.7)$ & $2727(19.5)$ \\
\hline Other antihypertensive agents & $66 \quad(0.8)$ & $107 \quad(1.0)$ & $133(1.1)$ & $85 \quad(1.0)$ & 140 \\
\hline Nitrates & $409 \quad(5.0)$ & $624 \quad(5.7)$ & $708 \quad(5.6)$ & $516 \quad(6.1)$ & 762 \\
\hline Statins & $4411(53.9)$ & $5717(52.3)$ & $6872(54.2)$ & $3957(47.1) \dagger$ & $7056(50.5)$ \\
\hline Digoxin & $196(2.4)$ & $320 \quad(2.9)$ & $320 \quad(2.5)$ & $286 \quad(3.4)$ & 405 (2.9) \\
\hline Amiodarone & $46 \quad(0.6)$ & $(0.8)$ & $(0.5)$ & $(0.7)$ & $(0.6)$ \\
\hline Warfarin & $349 \quad(4.3)$ & $593 \quad(5.4)$ & $619 \quad(4.9)$ & $407 \quad(4.8)$ & 629 \\
\hline Nonsteroidal anti-inflammatory drugs & $2257(27.6)$ & $3046(27.8)$ & $3500(27.6)$ & $2282(27.1)$ & $4027(28.8)$ \\
\hline \multicolumn{6}{|l|}{ Diabetes treatments used in previous $1 \mathrm{yr}$} \\
\hline Insulin & $709 \quad(8.7)$ & $1099(10.1)$ & $1412(11.1)$ & $907(10.8)$ & $1102 \quad(7.9)$ \\
\hline Metformin & $3683(45.0)$ & $4906(44.8)$ & $6096(48.0)$ & $3772(44.9)$ & $6526(46.7)$ \\
\hline Acarbose & $83(1.0)$ & $133 \quad(1.2)$ & $151 \quad(1.2)$ & $123 \quad(1.5)$ & 180 \\
\hline Pioglitazone & $263(3.2)$ & $321 \quad(2.9)$ & $368 \quad(2.9)$ & $136(1.6)$ & 333 \\
\hline Rosiglitazone & $213 \quad(2.6)$ & $293 \quad(2.7)$ & $381 \quad(3.0)$ & $197 \quad(2.3)$ & $352(2.5)$ \\
\hline Sulfonylureas & $2237(27.3)$ & $3277(30.0)$ & $4003(31.5)$ & $2758(32.8) \dagger$ & $4296(30.8)$ \\
\hline Repaglinide & $30 \quad(0.4)$ & $34 \quad(0.3)$ & $59 \quad(0.5)$ & $33(0.4)$ & $31 \quad(0.2)$ \\
\hline \multicolumn{6}{|l|}{ Income quintile } \\
\hline 1 (lowest) & $1815(22.2)$ & $2555(23.4)$ & $2912(23.0)$ & $1958(23.3)$ & $3213(23.0)$ \\
\hline 2 & $1798(22.0)$ & $2596(23.7)$ & $2813(22.2)$ & $1908(22.7)$ & $3240(23.2)$ \\
\hline 3 & $1691(20.7)$ & $2094(19.1)$ & $2534(20.0)$ & $1685(20.0)$ & $2825(20.2)$ \\
\hline 4 & $1473(18.0)$ & $1941(17.7)$ & $2269(17.9)$ & $1530(18.2)$ & $2536(18.2)$ \\
\hline 5 (highest) & $1374(16.8)$ & $1722(15.7)$ & $2113(16.6)$ & $1294(15.4)$ & $2112(15.1)$ \\
\hline Missing & $31 \quad(0.4)$ & $32 \quad(0.3)$ & $50 \quad(0.4)$ & $36(0.4)$ & $36 \quad(0.3)$ \\
\hline \multicolumn{6}{|l|}{ Specialty of prescribing physician } \\
\hline Family physician/general practitioner & 6376 (77.9) & $7967(72.8) \ddagger$ & $9519(75.0)$ & $5992(71.2) \dagger$ & $10867(77.8)$ \\
\hline Endocrinology & $206 \quad(2.5)$ & $247 \quad(2.3)$ & $293 \quad(2.3)$ & $182 \quad(2.2)$ & $172 \quad(1.2)$ \\
\hline Nephrology & $82 \quad(1.0)$ & $(2.1)$ & $(2.4)$ & $152 \quad(1.8)$ & $(0.6)$ \\
\hline Other & $632 \quad(7.7)$ & 1018 & $(7.9)$ & $745 \quad(8.9)$ & $1032 \quad(7.4)$ \\
\hline Unknown & $886(10.8)$ & 1475 (13.5) & 1581 & $1340(15.9) \dagger$ & $1809(13.0)$ \\
\hline $\begin{array}{l}\text { Note: IQR }=\text { interquartile range. } \\
\text { *Unless otherwise indicated. } \\
\text { tStandardized difference }>0.1 \text { between losarta } \\
\text { ₹Standardized difference }>0.1 \text { between candes }\end{array}$ & ups. & & & & \\
\hline
\end{tabular}


sis and procedure codes. We used the Ontario Health Insurance Plan database to identify claims for physician services, and the Ontario Diabetes Database to obtain information regarding diabetes diagnoses. This database is a validated administrative data registry of Ontario residents with diagnosed diabetes, which was generated from hospital records and physician services claims. The definition of at least 1 hospital admission or 2 physicians' claims with a diabetes diagnosis within a 2-year period has sensitivity of $86 \%$ and specificity of $97 \%$ for identifying people with diabetes (excluding gestational diabetes) in primary care records. ${ }^{14}$ Finally, we used the Institute for Clinical Evaluative Sciences Physician Database to determine physician specialties and the Registered Persons Database to obtain patient demographic data. These databases were linked in an anonymous fashion using encrypted health card numbers; they are regularly used for population-based drug research. ${ }^{15-18}$

\section{Identification of cohort}

We defined the index date as the date on which the first prescription for a study drug was dispensed. To restrict our analysis to patients taking these drugs for the first time, we excluded people who had received a prescription for any angiotensinreceptor blocker in the year preceding the index date. We also excluded patients who received their diagnosis of diabetes after they were given a pre-

\begin{tabular}{|c|c|c|c|c|}
\hline Drug & $n / N$ & $\begin{array}{c}\text { Unadjusted HR } \\
(95 \% \mathrm{Cl})\end{array}$ & $\begin{array}{c}\text { Adjusted HR } \\
(95 \% \mathrm{Cl})\end{array}$ & $\begin{array}{c}\text { Decreased Increased } \\
\longleftarrow \text { risk }\end{array}$ \\
\hline Irbesartan & $685 / 12691$ & 1.00 (ref) & 1.00 (ref) & p \\
\hline Telmisartan & $306 / 8182$ & $0.78(0.68-0.89)$ & $0.85(0.74-0.97)$ & $\rightarrow$ \\
\hline Candesartan & $603 / 10940$ & $1.04(0.93-1.16)$ & $0.99(0.89-1.11)$ & $\rightarrow$ \\
\hline Losartan & $467 / 8411$ & $1.00(0.89-1.13)$ & $0.93(0.83-1.05)$ & $\rightarrow$ \\
\hline \multirow[t]{3}{*}{ Valsartan } & 651/13 962 & $0.84(0.75-0.93)$ & $0.86(0.77-0.96)$ & $\bullet$ \\
\hline & & & & \multirow{2}{*}{ 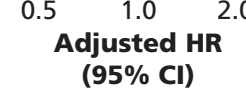 } \\
\hline & & & & \\
\hline
\end{tabular}

Figure 1: Risk of the composite outcome (admission to hospital for heart failure, acute myocardial infarction or stroke), by angiotensin-receptor blocker used among older adult patients with diabetes. Ratios were adjusted for all variables listed in Appendix 2 (available at www.cmaj.ca/lookup/suppl/doi:10.1503/cmaj $.121771 /-/ D C 1) . C I$ = confidence interval, $\mathrm{HR}=$ hazard ratio, ref $=$ reference. scription for an angiotensin-receptor blocker, patients who had a myocardial infarction in the 5 years preceding the start of treatment and patients who received an ACE inhibitor in conjunction with an angiotensin-receptor blocker.

We considered the use of an angiotensinreceptor blocker to be continuous if a prescription was refilled within 1.5-times the number of days of the preceding prescription's supply.

We included patients who switched between formulations of the same drug, but we censored those who either switched to a different angiotensin-receptor blocker during follow-up or who stopped treatment. We considered treatment to have stopped if a prescription was not refilled within 1.5-times the number of days of the preceding prescription's supply. In addition, we censored patients after 5 years of total observation time, at death or at the end of follow-up (Mar. 31, 2011), whichever occurred first.

\section{Outcome measures}

Our primary outcome was a composite of admission to hospital for acute myocardial infarction, heart failure or stroke. In secondary analyses, we determined the time to each outcome separately, as well as the time to death from any cause. For patients with multiple admissions to hospital during the study period, we considered only the first admission as an outcome. We determined dates of death using the Registered Persons Database and identified diagnoses during hospital admissions using the relevant codes from the 9th and 10th editions of the International Classification of Diseases (Appendix 1, available at www.cmaj.ca /lookup/suppl/doi:10.1503/cmaj.121771/-/DC1).

\section{Statistical analysis}

We calculated descriptive statistics for patients' baseline demographic and clinical characteristics and used standardized differences to test for intergroup differences. Standardized differences of less than 0.1 suggest good balance between groups for a given covariable. ${ }^{19}$

We conducted time-to-event analyses for the primary outcome using multivariable Cox proportional hazards regression to adjust for baseline demographic and clinical variables (Appendix 2, available at www.cmaj.ca/lookup/suppl/doi:10 .1503/cmaj.121771/-/DC1). We used patients taking irbesartan as the reference group. We selected irbesartan as the referent drug a priori because, like telmisartan, it has a long elimination half-life and has shown superior antihypertensive efficacy relative to comparative angiotensin-receptor blockers. ${ }^{20-24}$ Finally, we conducted a doseresponse assessment in which we considered low, medium and high doses of angiotensin-receptor 
blockers to be time-dependent covariables, using low-dose treatment as the reference. We verified the proportional hazards assumption by testing the statistical significance of a time-dependent treatment variable and by visually inspecting the estimated $\log (-\log )$ survival curves. All analyses were performed using SAS version 9.2.

This study was approved by the Research Ethics Board of the Sunnybrook Health Sciences Centre, Toronto, Ontario.

\section{Results}

We identified 54186 patients with diabetes who started treatment with an angiotensin-receptor blocker during the study period. Of these patients, $10940(20.2 \%)$ took candesartan, $12691(23.4 \%)$ took irbesartan, 8411 (15.5\%) took losartan, $8182(15.1 \%)$ took telmisartan and $13962(25.8 \%)$ took valsartan (Table 1). For the primary outcome, patients were collectively followed for a total of 107315 person-years of treatment. Overall, patients were highly similar with respect to demographic characteristics, the specialties of the prescribing physicians, comorbid illnesses and concomitant medications (Table 1).

In the main analysis, the primary outcome (admission to hospital for either acute myocardial infarction, heart failure or stroke) occurred in $2712(5.0 \%)$ patients taking an angiotensinreceptor blocker. After multivariable adjustment (Appendix 2), we found that telmisartan (adjusted hazard ratio [HR] $0.85,95 \%$ confidence interval [CI] 0.74-0.97) and valsartan (adjusted HR 0.86, 95\% CI 0.77-0.96) were associated with a significantly lower risk of the primary outcome when compared with irbesartan (Figure 1). In contrast, we found no difference in the risk of the primary outcome between irbesartan and either losartan (adjusted HR 0.93, 95\% CI 0.83-1.05) or candesartan (adjusted HR 0.99, 95\% CI 0.89-1.11) (Figure 1).

In the secondary analyses, we identified 2708 deaths, 1505 admissions to hospital for heart failure, 806 admissions for acute myocardial infarction and 804 admissions for stroke. We found a lower risk of heart failure with telmisartan versus irbesartan (adjusted HR 0.80, 95\% CI 0.66-0.96), but we saw no significant differences between angiotensin-receptor blockers in all other comparisons (Figure 2).

In the dose-response analysis, we found no differences in the risk of the primary outcome with either moderate (adjusted HR 1.04, 95\% CI 0.951.14) or high (adjusted HR 1.05 , 95\% CI 0.90 1.23) doses of angiotensin-receptor blockers relative to low doses of these drugs. Our main findings did not change appreciably after adjusting for dose (Appendix 3, available at www.cmaj.ca/lookup /suppl/doi:10.1503/cmaj.121771/-/DC1), although the effectiveness of valsartan was somewhat attenuated (adjusted HR 0.88, 95\% CI 0.77-1.0).

\section{Interpretation}

In this population-based study of more than 50000 older adult patients with diabetes starting treatment with an angiotensin-receptor blocker, we found that valsartan and telmisartan were associated with a reduced risk of admission to hospital for either stroke, myocardial infarction or heart failure relative to irbesartan. Furthermore, telmisartan was associated with a lower risk of admission to hospital for heart failure when compared with irbesartan. Our findings suggest that statistically important differences exist in the effectiveness of angiotensin-receptor blockers when used for the prevention of diabetes-related macrovascular disease, and that a class effect for these agents may not be assumed when used for this purpose in clinical practice.

Although angiotensin-receptor blockers share

\begin{tabular}{|c|c|c|c|}
\hline Drug & $n / N$ & $\begin{array}{c}\text { Adjusted HR } \\
(95 \% \mathrm{Cl})\end{array}$ & $\begin{array}{l}\text { Decreased Increased } \\
\longleftarrow \text { risk }\end{array}$ \\
\hline \multicolumn{4}{|c|}{$\begin{array}{l}\text { Admission to hospital for } \\
\text { myocardial infarction }\end{array}$} \\
\hline Irbesartan & 204/12 691 & 1.00 (ref) & T \\
\hline Telmisartan & $97 / 8182$ & $0.92(0.72-1.17)$ & \\
\hline Candesartan & 178/10 940 & $1.01(0.82-1.23)$ & \\
\hline Losartan & 139/8 411 & $0.96(0.78-1.20)$ & \\
\hline Valsartan & $188 / 13962$ & $0.85(0.70-1.04)$ & \\
\hline \multicolumn{4}{|l|}{$\begin{array}{l}\text { Admission to hospital } \\
\text { for stroke or TIA }\end{array}$} \\
\hline Irbesartan & 203/12 691 & 1.00 (ref) & \\
\hline Telmisartan & $92 / 8182$ & $0.84(0.66-1.08)$ & \\
\hline Candesartan & 174/10 940 & $0.98(0.80-1.20)$ & \\
\hline Losartan & $133 / 8411$ & $0.90(0.72-1.12)$ & $\longrightarrow$ \\
\hline \multicolumn{4}{|l|}{$\begin{array}{l}\text { Admission to hospital } \\
\text { for heart failure }\end{array}$} \\
\hline $\begin{array}{l}\text { for heart failure } \\
\text { Irbesartan }\end{array}$ & 374/12 691 & 1.00 (ref) & \\
\hline Telmisartan & $154 / 8182$ & $0.80(0.66-0.96)$ & $\bullet$ \\
\hline Candesartan & $346 / 10940$ & $1.02(0.88-1.19)$ & \\
\hline Losartan & $271 / 8411$ & $0.98(0.84-1.15)$ & - \\
\hline Valsartan & 360/13 962 & $0.87(0.75-1.00)$ & $\rightarrow$ \\
\hline \multicolumn{4}{|l|}{$\begin{array}{l}\text { Death } \\
\text { (all-cause mortality) }\end{array}$} \\
\hline Irbesartan & $659 / 12691$ & 1.00 (ref) & $\phi$ \\
\hline Telmisartan & 332/8 182 & $0.95(0.83-1.09)$ & $\rightarrow$ \\
\hline Candesartan & $600 / 10940$ & $1.05(0.94-1.17)$ & o- \\
\hline Losartan & $466 / 8411$ & $0.99(0.87-1.11)$ & -4 \\
\hline \multirow[t]{2}{*}{ Valsartan } & $651 / 13962$ & $0.90(0.80-1.00)$ & $\rightarrow$ \\
\hline & & & $\begin{array}{c}0.5 \underset{(95 \% \mathrm{Cl})}{1.0} \\
\text { Adjusted HR }\end{array}$ \\
\hline
\end{tabular}

Figure 2: Risk of individual outcomes (death, or admission to hospital for heart failure, acute myocardial infarction, or stroke), by angiotensin-receptor blockers used among older adult patients with diabetes. Ratios were adjusted for all variables listed in Appendix 2 (available at www.cmaj.ca/lookup/suppl/doi:10 $.1503 / \mathrm{cmaj} .121771 /-/ D C 1) . \mathrm{Cl}=$ confidence interval, $\mathrm{HR}=$ hazard ratio, ref = reference, $\mathrm{TIA}=$ transient ischemic attack. 
common structural features, important pharmacologic differences exist between the drugs that may explain our results. Specifically, at clinically attainable serum concentrations, telmisartan is unique among these drugs in its ability to structurally interact with and activate the PPAR $\gamma$ receptor, a ligand-activated transcription factor that regulates lipid metabolism and insulin sensitivity. ${ }^{825}$ Because telmisartan is a partial agonist of PPAR $\gamma$, it is not associated with the adverse effects typically seen with full agonists (e.g., thiazolidinediones), such as sodium and water retention, edema and heart failure. ${ }^{26,27}$

Randomized controlled trials and observational studies comparing cardiovascular outcomes and mortality among patients with diabetes taking individual angiotensin-receptor blockers are lacking. A previous observational study comparing 5 angiotensin-receptor blockers in patients with congestive heart failure found no difference in all-cause mortality between people using telmisartan and those using losartan, but the conclusions were limited by a small sample size (only 143 patients received telmisartan). ${ }^{28}$ Our study builds upon the results of smaller trials involving patients with diabetes in which telmisartan was associated with significantly greater reductions in serum lipid levels, plasma glucose concentration, glycated hemoglobin levels and markers of insulin resistance relative to other angiotensin-receptor blockers. . $^{9-13}$

In addition, we saw a reduced risk of our primary outcome among patients receiving valsartan. Although this effect was attenuated after adjusting for dose, some evidence suggests that valsartan may impart cardioprotective effects in patients with diabetes unrelated to dose or to the drug's efficacy as an antihypertensive agent. Valsartan has inhibited platelet aggregation in a manner that was neither dose- nor timedependent, an effect that was more pronounced among patients with diabetes relative to those without the disease. ${ }^{29}$

\section{Limitations}

As with all observational studies, it is possible that our results are biased by intergroup differences in the baseline risk of macrovascular disease and death. However, this seems unlikely, because all groups were highly similar with respect to baseline characteristics, such that any residual differences were negligible and unlikely to account for our results. Furthermore, we adjusted our analyses for an array of important clinical and sociodemographic predictors of angiotensin-receptor blocker use and macrovascular disease.

Although we had no access to clinical information such as smoking history or body mass index, these limitations apply equally to each of the angiotensin-receptor blockers we investigated. Thus, it is difficult to conceive of an unmeasured variable that would be strongly associated with our outcomes but distributed differentially among the various groups to an extent that could sufficiently compromise our findings. A large randomized controlled trial could conclusively show differences in efficacy among individual angiotensin-receptor blockers in patients with diabetes; however, conducting a trial comparing the efficacy of 5 distinct agents would be expensive and time consuming.

Although miscoding is another possible source of bias in observational studies, we used validated codes for identifying stroke, acute myocardial infection and heart failure in our databases, and differential miscoding among patients using angiotensin-receptor blockers is unlikely. ${ }^{30-32}$

Finally, our study involved patients with diabetes aged 66 years and older. Thus, our findings may not be applicable to younger patients or to patients with hypertension who do not have diabetes.

\section{Conclusion}

Our results suggest that telmisartan and valsartan are associated with a lower risk of admission to hospital for heart failure, stroke or acute myocardial infarction in older patients with diabetes. Pending confirmatory data from additional observational studies or randomized controlled trials, we suggest that a class effect may not be assumed when using angiotensin-receptor blockers for the prevention of diabetes-related macrovascular complications or heart failure, and that telmisartan and valsartan may be the preferred drugs for this indication.

\section{References}

1. Whiting DR, Guariguata L, Weil C, et al. IDF Diabetes atlas: global estimates of the prevalence of diabetes for 2011 and 2030. Diabetes Res Clin Pract 2011;94:311-21.

2. Laasko M, Lehto S. Epidemiology of macrovascular disease in diabetes. Diabetes Rev 1997;5:294-315.

3. Vijan S, Hayward RA. Treatment of hypertension in type 2 diabetes mellitus: blood pressure goals, choice of agents, and setting priorities in diabetes care. Ann Intern Med 2003;138:593-602.

4. Probstfield JL, O'Brien KD. Progression of cardiovascular damage: the role of renin-angiotenisn system blockade. Am J Cardiol 2010;105(Suppl):10A-20A

5. Schmieder RE, Hilgers KF, Schlaich MP, et al. Renin-angiotensin system and cardiovascular risk. Lancet 2007;369:1208-19.

6. Matchar DB, McCrory DC, Orlando LA, et al. Systematic review: comparative effectiveness of angiotensin-converting enzyme inhibitors and angiotensin II receptor blockers for treating essential hypertension. Ann Intern Med 2008;148:16-29.

7. Frampton JE. Telmisartan: a review of its use in cardiovascular disease prevention. Drugs 2011;71:651-77.

8. Benson SC, Pershadsingh HA, Ho CI, et al. Identification of telmisartan as a unique angiotensin II receptor antagonist with selective PPAR $\gamma$-modulating activity. Hypertension 2004;43: 993-1002.

9. Vitale C, Mercuro G, Castiglioni C, et al. Metabolic effect of telmisartan and losartan in hypertensive patients with metabolic syndrome. Cardiovasc Diabetol 2005;4:6. 
10. Derosa G, Fogari E, D'Angelo A, et al. Metabolic effects of telmisartan and irbesartan in type 2 diabetic patients with metabolic syndrome treated with rosiglitazone. J Clin Pharm Ther 2007;32:261-8.

11. Negro R, Formoso G, Hassan H. The effects of irbesartan and telmisartan on metabolic parameters and blood pressure in obese, insulin resistant, hypertensive patients. J Endocrinol Invest 2006;29:957-61.

12. Derosa G, Ragonesi PD, Mugellini A, et al. Effects of telmisartan compared with eprosartan on blood pressure control, glucose metabolism and lipid profile in hypertensive, type 2 diabetic patients: a randomized, double-blind, placebo-controlled 12 month study. Hypertens Res 2004;27:457-64.

13. Ichikawa Y. Comparative effects of telmisartan and valsartan on insulin resistance in hypertensive patients with metabolic syndrome. Intern Med 2007;46:1331-6.

14. Hux JE, Ivis F, Flintoft V, et al. Diabetes in Ontario: determination of prevalence and incidence using a validated administrative data algorithm. Diabetes Care 2002;25:512-6

15. Lipscombe LL, Gomes T, Lévesque LE, et al. Thiazolidinediones and cardiovascular outcomes in older patients with diabetes. JAMA 2007;298:2634-43

16. Park-Wyllie LY, Juurlink DN, Kopp A, et al. Outpatient gatifloxacin therapy and dysglycemia in older adults. $N$ Engl $\mathrm{J} \mathrm{Med}$ 2006;354:1352-61.

17. Juurlink DN, Gomes T, Lipscombe LL, et al. Adverse cardiovascular events during treatment with pioglitazone and rosiglitazone: population based cohort study. BMJ 2009;339:b2942.

18. Gomes T, Mamdani MM, Dhalla IA, et al. Opioid dose and drug-related mortality in patients with nonmalignant pain. Arch Intern Med 2011;171:686-91

19. Austin PC, Grootendorst P, Anderson GM. A comparison of the ability of different propensity score models to balance measured variables between treated and untreated subjects: a Monte Carlo study. Stat Med 2007;26:734-53.

20. Farsang C. Indications for and utilization of angiotensin receptor II blockers in patients at high cardiovascular risk. Vasc Health Risk Manag 2011;7:605-22.

21. Smith DH, Cramer MJ, Neutel JM, et al. Comparison of telmisartan versus losartan: meta-analysis of titration-to-response studies. Blood Press Monit 2003;8:111-7.

22. Lacourcière Y, Krzesinski JM, White MB, et al. Sustained antihypertensive activity of telmisartan compared with valsartan. Blood Press Monit 2004;9:203-10.

23. Oparil S, Guthrie R, Lewin AJ, et al. An elective-titration study of the comparative effectiveness of two angiotensin II-receptor blockers, irbesartan and losartan. Clin Ther 1998;20:398-409.

24. Bobrie G, Delonca J, Moulin C, et al. A home blood pressure monitoring study comparing the antihypertensive efficacy of two angiotensin II receptor antagonist fixed combinations. Am J Hypertens 2005; 18:1482-8.

25. Duan SZ, Ivashchenko CY, Usher MG, et al. PPAR-gamma in the cardiovascular system. PPAR Res 2008;2008:745804.

26. Kurtz TW. Treating the metabolic syndrome: telmisartan as a peroxisome proliferator-activated receptor- $\gamma$ activator. Acta Diabeto 2005;42:S9-16.

27. Schupp M, Clemenz M, Gineste R, et al. Molecular characterization of new selective peroxisome proliferators-activated receptor- $\gamma$ modulators with angiotensin receptor blocking activity. Diabetes 2005;54:3442-52.

28. Hudson M, Humphries K, Tu JV, et al. Angiotensin II receptor blockers for the treatment of heart failure: A class effect? Pharmacotherapy 2007;27:526-34.

29. Serebruany VL, Pokov AN, Malinin AI, et al. Valsartan inhibits platelet activity at different doses in mild to moderate hypertensives: Valsartan Inhibits Platelets (VIP) trial. Am Heart J 2006;151:92-9.

30. Austin PC, Daly PA, Tu JV. A multicenter study of the coding accuracy of hospital discharge administrative data for patients admitted to cardiac care units in Ontario. Am Heart $J$ 2002;144: 290-6.

31. Juurlink DN, Preyra C, Croxford R, et al. Canadian Institute for Health Information discharge abstract database: a validation study. Toronto (ON): Institute for Clinical Evaluative Sciences; 2006.

32. Jha P, Deboer D, Sykora K, et al. Characteristics and mortality outcomes of thrombolysis trial participants and nonparticipants: a population-based comparison. J Am Coll Cardiol 1996;27: 1335-42.

Affiliations: Department of Family and Community Medicine (Antoniou), St. Michael's Hospital; Keenan Research Centre in the Li Ka Shing Knowledge Institute (Antoniou, Gomes, Mamdani), St. Michael's Hospital; University of Toronto (Antoniou, Gomes, Juurlink, Mamdani); Institute for Clinical Evaluative Sciences (Camacho, Yao, Gomes, Juurlink); Sunnybrook Research Institute (Juurlink); Applied Health Research Centre (Mamdani), St. Michael's Hospital, Toronto, Ont.

Contributors: Tony Antoniou, Ximena Camacho, Tara Gomes, David Juurlink and Muhammad Mamdani conceived and designed the study. Tony Antoniou, Ximena Camacho, Tara Gomes, David Juurlink, Muhammad Mamdani and Zhan Yao analyzed and interpreted the data. Ximena Camacho and Zhan Yao acquired the data. Tony Antoniou drafted the manuscript. Tony Antoniou, Ximena Camacho, Tara Gomes, David Juurlink, Muhammad Mamdani and Zhan Yao critically revised the manuscript for important intellectual content. All authors approved the final version of the manuscript submitted for publication. Tony Antoniou is the guarantor of this work and, as such, had full access to all of the data in the study and takes responsibility for the integrity of the data and the accuracy of its analysis.

Funding: Tony Antoniou is supported by a postdoctoral fellowship from the Ontario HIV Treatment Network. This project was supported by research funds from the Ontario Drug Policy Research Network and by the Institute for Clinical Evaluative Sciences, which is funded by a grant from the Ontario Ministry of Health and Long-Term Care. The sponsors had no role in the design and conduct of the study; in the collection, analysis and interpretation of the data; or in the preparation, review or approval of the manuscript. The opinions, results and conclusions reported in this paper are those of the authors and are independent from the funding sources. No endorsement by the Institute for Clinical Evaluative Sciences or the Ontario Ministry of Health and Long-Term Care is intended or should be inferred.

Acknowledgements: The authors thank Brogan Inc., Ottawa, Ontario, for use of their Drug Product and Therapeutic Class Database, and Jennifer Levi, Institute for Clinical Evaluative Sciences, for administrative assistance in the preparation of this manuscript. 